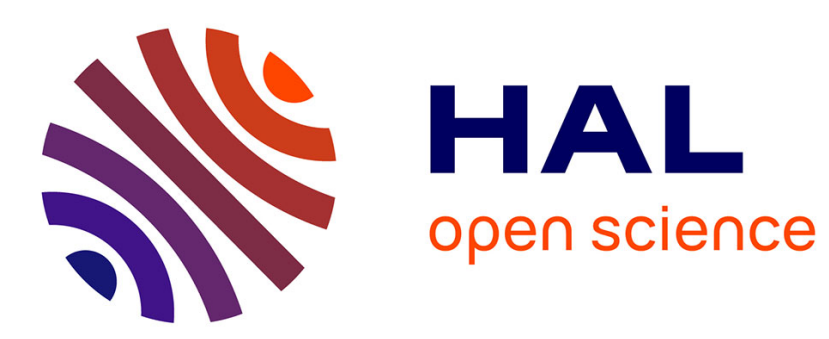

\title{
Floating Body and Hot Carrier Effects in Ultra-Thin Film SOI MOSFETs
}

\author{
S.-H. Renn, C. Raynaud, F. Balestra
}

\section{To cite this version:}

S.-H. Renn, C. Raynaud, F. Balestra. Floating Body and Hot Carrier Effects in Ultra-Thin Film SOI MOSFETs. Journal de Physique IV Proceedings, 1996, 06 (C3), pp.C3-49-C3-54. 10.1051/jp4:1996307 . jpa-00254225

\section{HAL Id: jpa-00254225 https://hal.science/jpa-00254225}

Submitted on 1 Jan 1996

HAL is a multi-disciplinary open access archive for the deposit and dissemination of scientific research documents, whether they are published or not. The documents may come from teaching and research institutions in France or abroad, or from public or private research centers.
L'archive ouverte pluridisciplinaire HAL, est destinée au dépôt et à la diffusion de documents scientifiques de niveau recherche, publiés ou non, émanant des établissements d'enseignement et de recherche français ou étrangers, des laboratoires publics ou privés. 


\title{
Floating Body and Hot Carrier Effects in Ultra-Thin Film SOI MOSFETs
}

\author{
S.-H. Renn, C. Raynaud* and F. Balestra \\ LPCS/ENSERG-INPG (UMR CNRS), BP 257, 38016 Grenoble, France \\ * LETI-CEA (DMEL/CENG), 38041 Grenoble, France
}

\begin{abstract}
Floating body and hot carrier effects are thoroughly investigated in deep submicron N- and P-channel ultra-thin film SOI MOSFETs for a wide temperature range. A strong reduction of the parasitic bipolar transistor is obtained with decreasing the temperature (at $77 \mathrm{~K}$ ) and with a grounded substrate. However, the action of the PBT is not completely suppressed even at $77 \mathrm{~K}$ with a body terminal. Substantial deviations from the traditional bell-shaped curves are found for the substrate current in N- and P- channel SOI devices and are attributed to the PBT carrier transport. The influence of these special SOI mechanisms on gate current is also underlined. Finally, original variations of hot carrier effects as a function of the temperature are shown and explained by the aforementioned SOI electrical properties and the differences between inversion and accumulation-mode devices.
\end{abstract}

\section{INTRODUCTION}

The study of floating body phenomena, mainly the kink effect and the parasitic bipolar transistor (PBT) leading to latch and premature breakdown, is of great interest for SOI MOSFETs. When the body terminal is grounded, these parasitic effects are supposed to be suppressed. However, for moderately thin film fully depleted devices, the body contact is not completely efficient for hole collection (for a Nchannel) leading to a kink effect in the case of a grounded substrate [1,2]. In the case of ultra-thin Si film the efficiency of a grounded body has not been evaluated. Furthermore, at low temperature, impurity freeze-out can also affect the ability of the contact to collect carriers. On the other hand, the analysis of hot carrier effects is also necessary for the prediction of the long term reliability of MOS devices [3]. Some correlation exists between floating body phenomena and hot carrier effects, but this has not been studied in detail. The variations of hot carrier effects in SOI MOSFET with temperature need also a careful evaluation. The aim of this paper is to present a thorough investigation of the floating body effects, the gate and substrate currents, and the influence of body contact in a wide range of temperature (down to near liquid helium temperature), channel lengths (down to $0.2 \mu \mathrm{m}$ ) and Si film (down to $20 \mathrm{~nm}$ ).

\section{RESULTS AND DISCUSSION}

Fig. 1 shows the transfer characteristics (forward and reverse Vg-scans) for a $0.2 \mu \mathrm{m}$ NMOS SIMOXMOSFET ( $4.5 \mathrm{~nm}$ gate oxide) with a $40 \mathrm{~nm}$ Si film thickness (enhancement-mode transistor). At $300 \mathrm{~K}$ (Fig. 1a), for a drain bias larger than $3 \mathrm{~V}$, a clear latch phenomenon is obtained for small gate biases with a very large leakage current in accumulation. Fig. $1 \mathrm{~b}$ presents the behavior of the same device at liquid nitrogen temperature. A substantial reduction of this parasitic effect is observed up to a drain voltage of $3.5 \mathrm{~V}$. Nevertheless, the latch phenomenon is not completely suppressed and can be seen for $\mathrm{Vd}=3.5 \mathrm{~V}$. In Fig. 2 are plotted the variations of $\mathrm{Id}(\mathrm{Vg})$ obtained with a grounded substrate. A significant decrease of the latch effect is found compared with Fig. 1a at $300 \mathrm{~K}$ (Fig. 2a), showing that the body terminal is useful 
for hole collection. However, the action of the parasitic bipolar transistor is not completely suppressed, even in the $77 \mathrm{~K}$ range (Fig. $2 \mathrm{~b}$ ), which demonstrates experimentally the limits of this contact for ultrathin SOI layers. For a $20 \mathrm{~nm}$ Si film enhancement-mode $\mathrm{N}$-channel devices, similar improvements of the PBT effects have been found at low temperature.

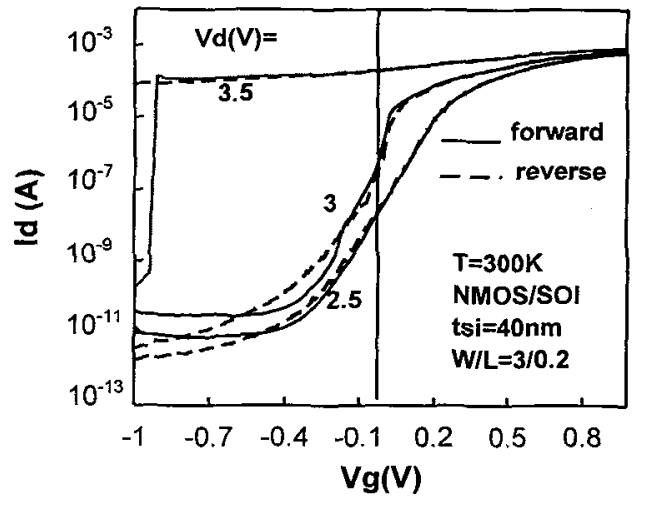

(a)

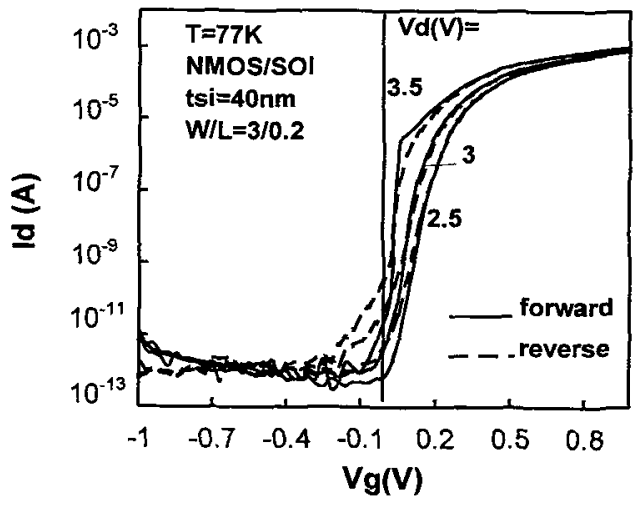

(b)

Fig. 1 : Transfer characteristics for a $\mathrm{N}$-channel enhancement-mode SIMOX MOSFET at (a) $300 \mathrm{~K}$ and (b) $77 \mathrm{~K}$ with forwardand reverse- $\mathrm{Vg}$ scans $(\mathrm{tsi}=40 \mathrm{~nm}, \mathrm{~W} / \mathrm{L}=3 / 0.2$ ).

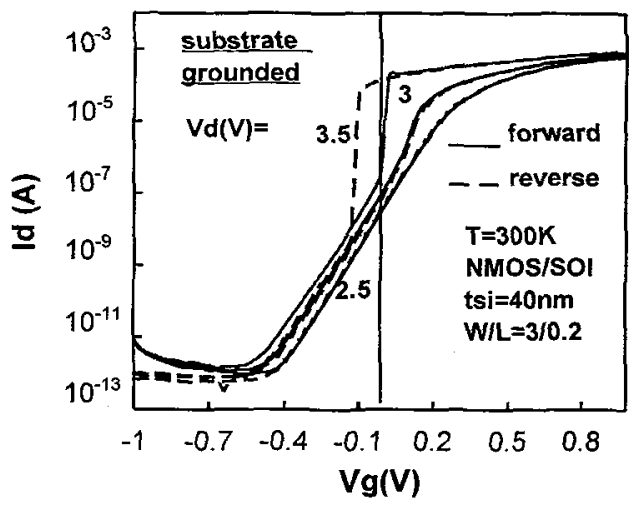

(a)

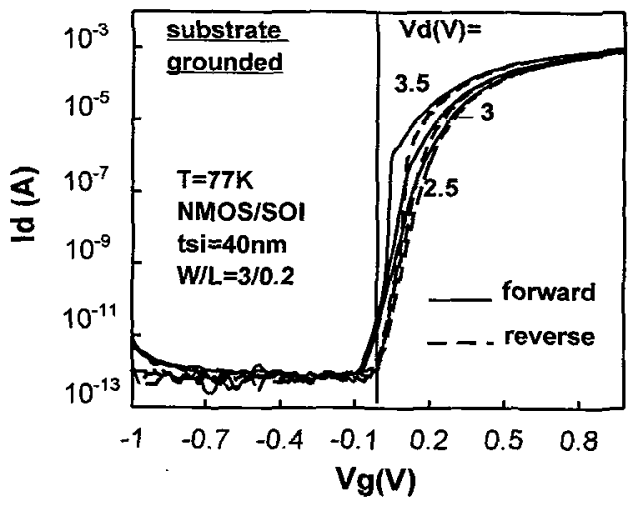

(b)

Fig. 2 : Transfer characteristics for a N-channel enhancement-mode SIMOX MOSFET at (a) $300 \mathrm{~K}$ and (b) $77 \mathrm{~K}$ with forwardand reverse- $\mathrm{Vg}$ scans and a grounded body contact $(\mathrm{tsi}=40 \mathrm{~nm}, \mathrm{~W} / \mathrm{L}=3 / 0.2)$.

For accumulation-mode p-channel SIMOX-MOSFETs, the improvement of this harmful effect induced by a temperature reduction is not as large as in the case of inversion-mode transistors (Fig. 3a-b). This confirms the results previously obtained for low temperature operation of accumulation-mode SOI MOSFETs fabricated with thicker Si film [4]. A grounded substrate also allows to substantially reduce the latch phenomenon (Fig. 4a-b) as in the case of N-channel transistors (Fig. 2). These interesting behaviors for a cryogenic operation have been attributed to the exponential reduction of the gain $\beta$ of the parasitic bipolar transistor with reducing the temperature, and to the partial freeze-out of the lightly doped drain and the lightly doped source inducing a decrease of the impact ionization and $\beta$, respectively. 


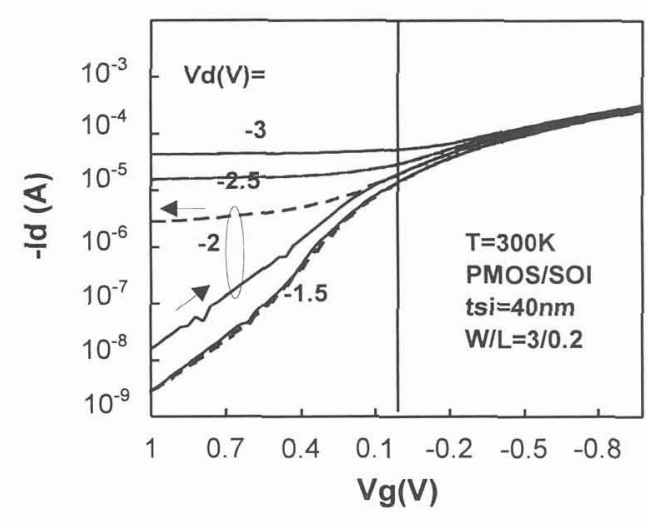

(a)

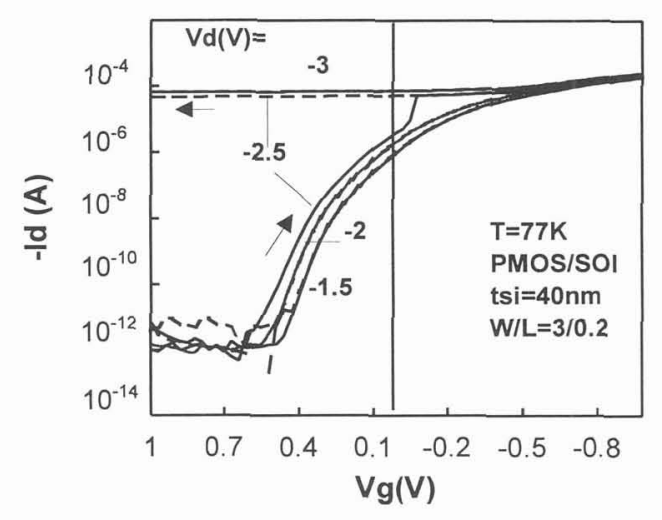

(b)

Fig. 3 : Transfer characteristics for a P-channel accumulation-mode SIMOX MOSFET at (a) 300K and (b) 77K with forwardand reverse $-\mathrm{Vg}$ scans $(\mathrm{tsi}=40 \mathrm{~nm}, \mathrm{~W} / \mathrm{L}=3 / 0.2$ ).

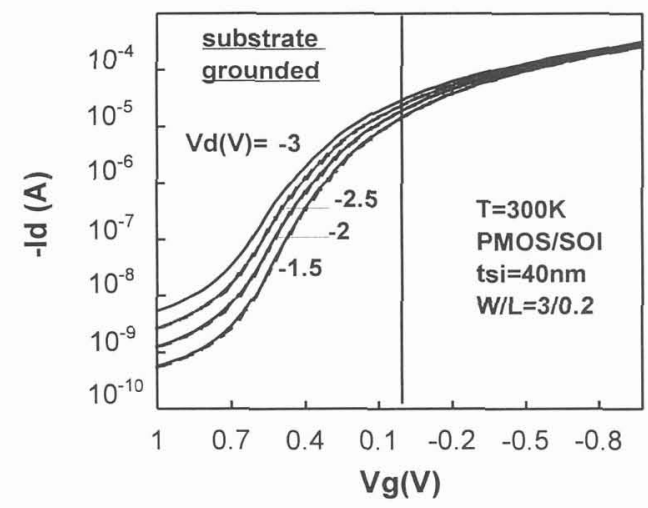

(a)

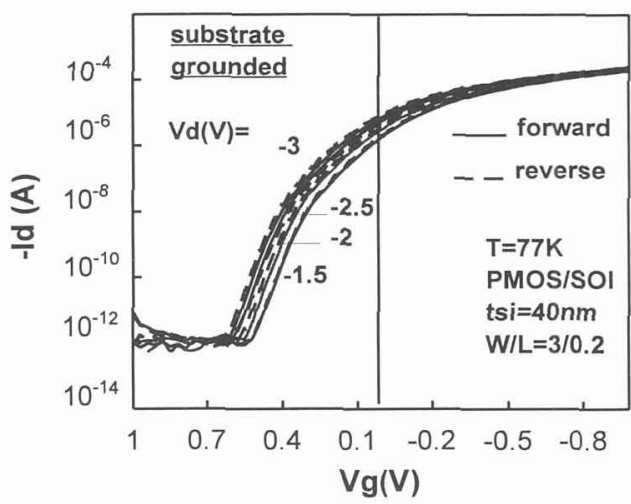

(b)

Fig. 4 : Transfer characteristics for a P-channel accumulation-mode SIMOX MOSFET at (a) 300K and (b) 77K with forwardand reverse- $\mathrm{Vg}$ scans and a grounded body contact $(\mathrm{tsi}=40 \mathrm{~nm}, \mathrm{~W} / \mathrm{L}=3 / 0.2)$.

The study of hot carrier effects is exemplified in Figs. 5-9. Fig. 5 presents the substrate current variations with Vg for a N-channel device at 300 and $77 \mathrm{~K}$. At high drain bias, for both temperatures, the PBT action leads to a deviation from the traditional bell-shaped curves. The maximum substrate current is shown for NMOS and PMOS transistors $(0.2 \mu \mathrm{m}$ channel length) for various temperatures (Figs. 6,8). In N-channel SIMOX-MOSFETs (Fig. 6), a strong decrease of Ibmax is obtained with reducing the temperature. It has been shown for bulk Si N-channel MOSFETs that the substrate current and impact ionization rate can be reduced at low temperature in the low drain voltage range $(\mathrm{Vd}<2 \mathrm{~V})[5-7]$, this behavior being enhanced with reducing the channel length [8]. In the results presented in this work, the maximum substrate current decreases with reducing the temperature for a drain bias up to $4 \mathrm{~V}$. Two different regimes can be observed in these plots. Indeed, the second part of the curves (for $\mathrm{Vd}>3 \mathrm{~V}$ ), which is especially clear at $77 \mathrm{~K}$ and $25 \mathrm{~K}$, presents a different variation with Vd. This behavior is associated with the parasitic bipolar transistor, which also leads to hot carrier effects, and induces additional impact ionization at high drain biases (Fig. 5). In fact, as it has been shown in Fig. 2, the PBT cannot be completely suppressed with a grounded body contact. 


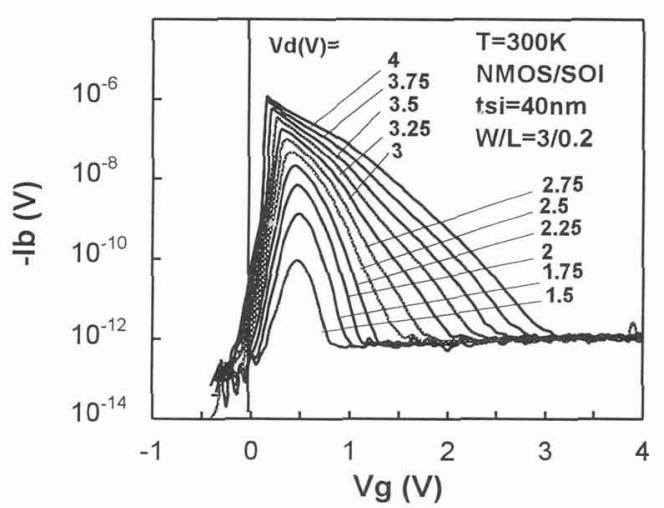

(a)

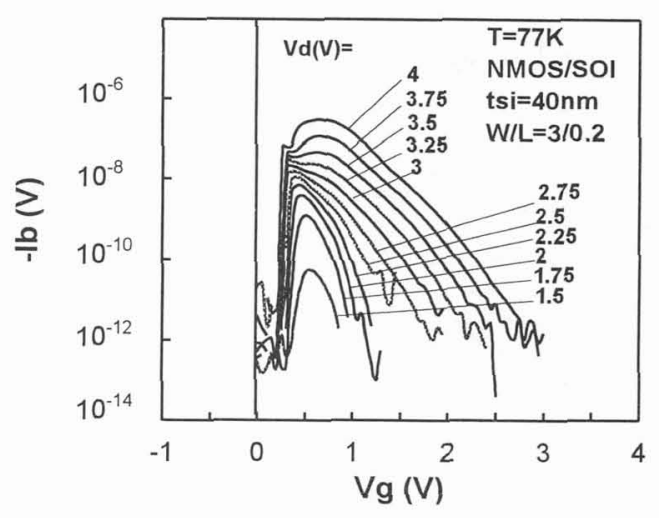

(b)

Fig. 5 : Variations of the substrate current as a function of gate voltage for a N-channel enhancement-mode SIMOX MOSFET at (a) $300 \mathrm{~K}$ and (b) $77 \mathrm{~K}$ (tsi=40nm, W/L=3/0.2).

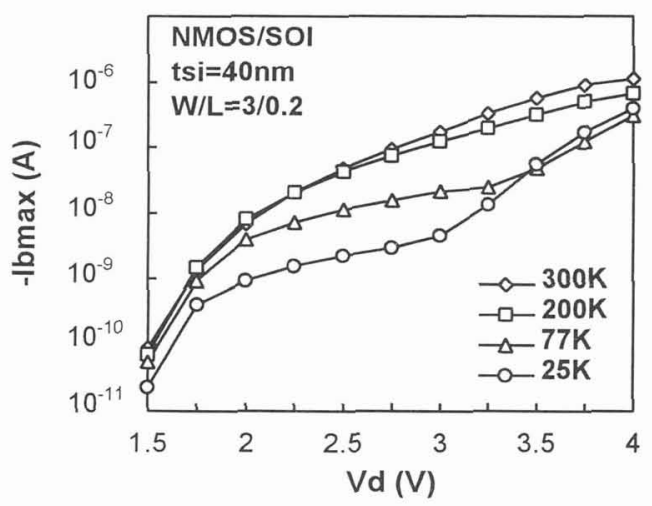

Fig. 6 : Maximum substrate current versus drain bias for various temperatures (enhancement-mode NMOS/SOI, tsi $=40 \mathrm{~nm}, \mathrm{~W} / \mathrm{L}=3 / 0.2$ )

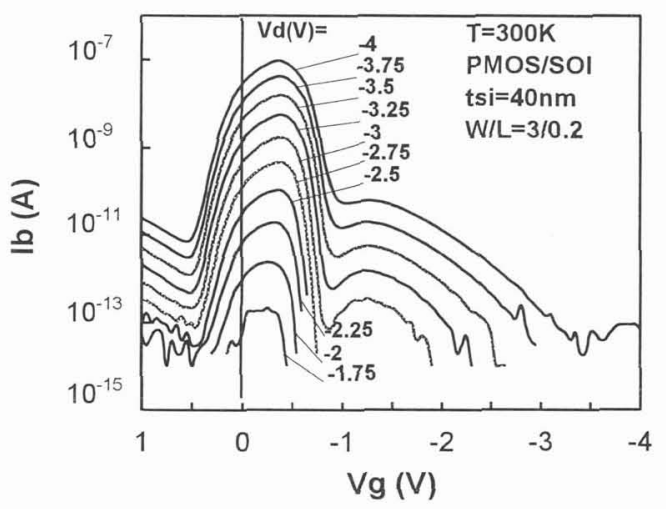

(a)

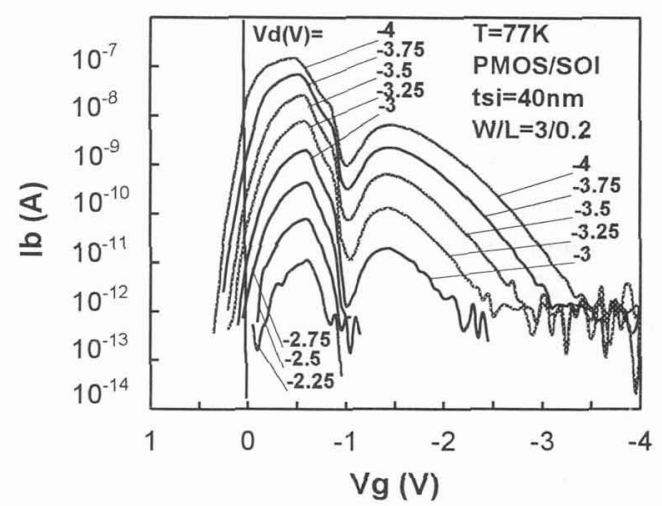

(b)

Fig. 7 : Variations of the substrate current as a function of gate voltage for a P-channel accumulation-mode SIMOX MOSFET at (a) $300 \mathrm{~K}$ and (b) $77 \mathrm{~K}(\mathrm{tsi}=40 \mathrm{~nm}, \mathrm{~W} / \mathrm{L}=3 / 0.2)$. 


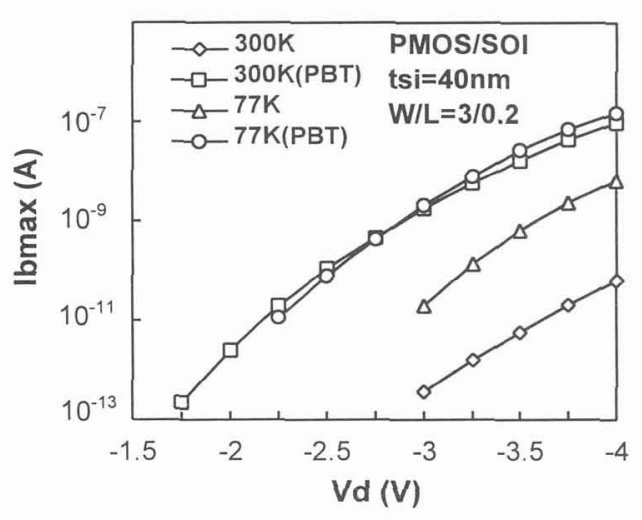

Fig. 8 : Maximum substrate current versus drain bias for various temperatures (accumulation-mode PMOS/SOI, $\mathrm{tsi}=40 \mathrm{~nm}, \mathrm{~W} / \mathrm{L}=3 / 0.2$ )

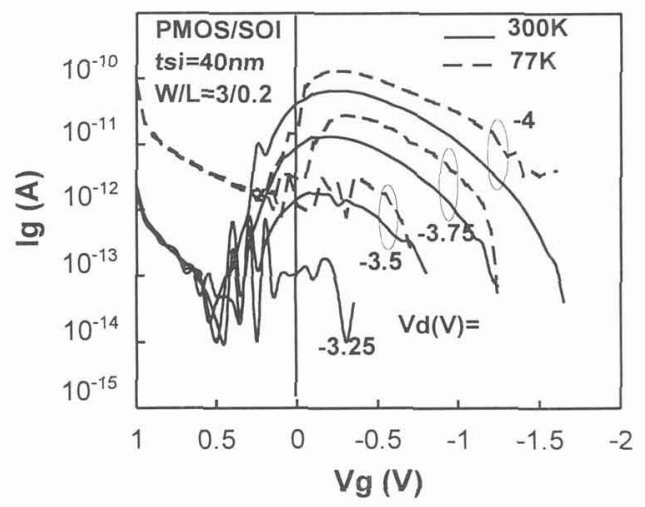

Fig. 9: Variations of the gate current as a function of the gate voltage for various temperatures and drain biases (accumulation-mode PMOS/SOI, tsi=40nm, W/L=3/0.2).

These two regimes, impact ionization due to MOS and PBT carrier transport, are clearly illustrated in Fig. 7 for accumulation-mode PMOS devices at 300 and $77 \mathrm{~K}$. The first substrate current peak is due to the PBT effect, and the second one is associated with the conventional impact ionization in a MOS channel. It is worth noticing that the effect of a temperature variation is very different between N (Fig. 6) and P (Fig. 8) channel MOSFETs. In this last case, Ibmax is almost constant in the PBT regime, and increases with reducing the temperature in the MOS regime, highlighting different physical mechanisms depending on the channel ( $\mathrm{N}$ or $\mathrm{P}$ ), device type (inversion or accumulation), and the operation regime (MOS or PBT). The gate current for P-MOS SIMOX-MOSFETs is also presented at two temperatures in Fig. 9. This gate electron current is associated with the parasitic bipolar action and is observed in the same gate voltage range as the first substrate current peak in Fig. 7. The gate current being associated with high energy carrier which overcome the $\mathrm{Si} / \mathrm{SiO}_{2}$ barrier height, the drain bias for which the gate current threshold is obtained is significantly higher than that leading to the substrate current threshold (Fig. 7).

\section{Conclusion}

Floating body and hot carrier effects have been thoroughly investigated in deep submicron $\mathrm{N}$ - and Pchannel ultra-thin film SOI MOSFETs for a wide temperature range. A strong reduction of the parasitic bipolar transistor has been obtained with decreasing the temperature (at 77K) and with a grounded substrate. However, the action of the PBT is not completely suppressed even at $77 \mathrm{~K}$ with a body terminal. Substantial deviations from the traditional bell-shaped curves have been found for the substrate current in $\mathrm{N}$ - and P- channel SOI devices and have been attributed to the PBT carrier transport. The influence of these special SOI mechanisms on gate current has also been underlined. Finally, original variations of hot carrier effects as a function of the temperature have been shown and explained by the aforementioned SOI electrical properties and the differences between inversion and accumulation-mode devices.

\section{References}

[1] F. Balestra, T. Matsumoto, M. Tsuno, H. Nakabayashi, Y. Inoue, M. Koyanagi, Electron. Lett. 31, p. 326,1995

[2] M. Koyanagi, T. Matsumoto, T. Shimatani, F. Balestra, Y. Hiruma, M. Okabe, Y. Inoue, IEDM Tech. Dig., p. 944, 1994 
[3] C. Hu, S.C. Tam, F.-C. Hsu, P.-K. Ko, T.-Y. Chan, K.W. Terrill, IEEE TED-32, p. 375, 1985

[4] F. Balestra, J. Jomaah, G. Ghibaudo, O. Faynot, A.J. Auberton-Hervé, B. Giffard, IEEE TED-41, p. 109, 1994

[5] B. Eitan, D. Froman-Bentchkowsky, J. Shappir, J. Appl. Phys. 53, p. 1244, 1982

[6] A.K. Henning, N.N. Chan, J.T. Watt, J.D. Pummer, IEEE Trans. Electron Dev. 34, p. 64, 1987

[7] S.I. Takagi, A. Toriumi, IEDM Tech. Dig., p. 711, 1992

[8] F. Balestra, T. Matsumoto, M. Tsuno, H. Nakabayashi, M. Koyanagi, IEEE EDL-16, p. 433, 1995 